\title{
Effects of Minor Components of Olive Oil on Health
}

\author{
Sameh Ben Khedir ${ }^{1 *}$, Dorsaf Moalla², Masarra Mzid ${ }^{1}$, Zouheir Sahnoun ${ }^{2}$ and Tarek Rebai ${ }^{1}$ \\ ${ }^{1}$ Research Unit Histology Embryology and Reproductive Biology, University of Sfax, Tunisia \\ ${ }^{2}$ Research Unit Pharmacology, University of Sfax, Tunisia
}

Submission: November 30, 2017; Published: January 31, 2018

*Corresponding author: Sameh Ben Khedir, Faculty of Medicine of Sfax, University of Sfax, Avenue Majida Boulila 3029 Sfax, Tunisia, Tel: (+216) 74241 888; Fax: (+ 216)74 246 217; Email: samehbkh@yahoo.fr

\begin{abstract}
There are various disagreements about fats in the diet. But, pretty much everyone agrees that olive oil, especially extra virgin, is good for health. Here are many health benefits of olive oil that are supported by scientific research. Olive oil is rich in monousatured oleic acid, which is believed to have many beneficial effects. Apart from its beneficial fatty acids, it contains minor components such as phytosterols, carotenoids, tocopherols and hydrophilic phenols. These compounds offer antioxidant, anti-inflammatory and anti bacterial proprietors for the oil, which may be the main reasons for its health benefits.
\end{abstract}

Keywords: Olive oil; Tocophrols; Phenolic compounds; Anti-oxidant; Anti anflammatory; Health benefits

\section{Introduction}

Olive oil is a liquid extracted from olives (the fruit of Olea europaea; family Oleaceae). In the Mediterranean diet it is commonly used in cooking, whether for frying, or as a salad dressing for its possible health benefits. In addition, olive oil is used in cosmetics, pharmaceuticals, and soaps. Olive oil is characterized by its delicate and unique fragrance. This very special flavor is due to a whole range of components present at very low concentrations. If the oil consists essentially of fatty acids linked to glycerol ( $>95 \%$ ), that is to say triglycerides, it also contains a large number of other components, present in low quantities. These so-called "minor" components are nonetheless very important: some have beneficial effects on human health, others enhance the stability of the oil and, far from negligible, and others are responsible for its unique fragrance. The minor components of the olive oil can be separated into tocopherols, phenols, aromatic, hydrocarbons and sterols. This document reviews the first three categories to study their role in human health and their contribution to oil stability and taste.

\section{Minor Components of Olive Oil}

\section{Tocopherols}

The type of vitamin $\mathrm{E}$ found in olive oil is alpha tocopherol at levels ranging from 1.2 to $43 \mathrm{mg} / 100 \mathrm{~g}$ [1-3]. One tablespoon of olive oil contains 1.9 milligrams of vitamin $\mathrm{E}$, which is 10 percent of the daily value of this nutrient based on a 2,000-calorie diet. Obviously, the amount of these molecules present in the oil is a function of several factors. Although the scientific evidence on this point is relatively thin, it seems that olive variety and maturity as well as conditions and $(\beta$ and $\beta$ ) are present only in trace amount [1-3].

\section{Phenolic compounds}

The pulp of the olive contains phenolic compounds, which are amounts are found in the oil. The class of phenols includes a variety of substances, including simple phenolic compounds such as vanillic acid, gallic acid, coumaric acid, caffeic acid, tyrosol and hydroxytyrosol. On average, these simple phenols are present at a concentration of $4.2 \mathrm{mg} / 100 \mathrm{~g}$ in extra virgin olive oil and $0.47 \mathrm{mg} / 100 \mathrm{~g}$ in refined oil. In addition, olive oil contains secoiridoids such as oleuropein and ligstroside (respectively $2.8 \mathrm{mg} / 100 \mathrm{~g}$ in extra virgin oil and $0.93 \mathrm{mg} / 100 \mathrm{~g}$ in refined oil), or more molecules Such as lignans $(4.15 \mathrm{mg} / 100 \mathrm{~g}$ in extra virgin oil and $0.73 \mathrm{mg} / 100 \mathrm{~g}$ in refined oil) and flavonoids such as apigenin or luteolin (data from [4]. The quantity of phenolic compounds in olive oil depends on several factors, including cultivar, degree of maturation, possible infestation by the olive fly Dacus Olea, and climate [5]. The levels of hydroxytyrosol, tyrosol and luteolin increase with fruit maturity [6], while the total amount of phenolic compounds and of tocopherol decreases [2]. Until now, the bioavailability of these substances has been little studied. Visioli and his team observed that tyrosol and hydroxytyrosol are absorbed in a dose-dependent manner, $60-80 \%$ of the ingested amount [7] 


\section{Aromatic compounds}

It is estimated that more than 70 compounds contribute to the particular fragrance and taste of olive oil. These include degradation products of unsaturated fatty acids such as aldehydes (in particular hexanal, nonanal, 1-hexanol or 2, 4-decadienal). In addition, aliphatic and aromatic hydrocarbons, alcohols, ketones, ethers, esters and furans and thioterpene derivatives contribute significantly to the odor and flavor of the oil [1].

\section{Impact of Minor Compounds on Human Health}

Olive oil is an integral ingredient of the Mediterranean diet and accumulating evidence suggests that it may have health benefits which include reduction of risk factors of coronary heart disease, prevention of several types of cancers, and modification of immune and inflammatory responses. Olive oil can be considered as an example of a functional food, with a variety of components that may contribute to overall therapeutic characteristics [8]. Its nutritional and healthy values and pleasant flavour have contributed to an increase of its in consumption. The nutritional value of VOO happen from high levels of oleic acid, and from minor components such as phytosterols, carotenoids, tocopherols and hydrophilic phenols [9].

\section{Tocopherols}

Oxidative damage is considered to play a key role in the development of several diseases such as coronary artery disease and cancer, and arguments suggesting that antioxidants protect against these lesions and the oxidation of low density lipoproteins have increased Strength in recent years. Since the 1980s, several epidemiological studies have been carried out to evaluate the link between vitamin $\mathrm{E}$ intake and cardiovascular disease. These studies included vitamin E supplementation at high doses and not on a diet rich in vitamin $\mathrm{E}$. It has been found that high-dose vitamin E supplementation (> 67mg a-tocopherol/day) during At least two years significantly lowered the risk of coronary artery disease (31\% to $65 \%$ ) [10]. In contrast, short-term or low-dose supplements $(<67 \mathrm{mg} / \mathrm{d})$ had no effect on coronary artery disease [11].

In contrast to these results from observational studies, completed intervention trials have not yet yielded unquestionable results. In the Cambridge Heart Antioxidant Study (Cambridge Heart Antioxidant Study [CHAOS]), administration of 268 or $536 \mathrm{mg}$ of-tocopherol per day resulted in a substantial decrease in the incidence of infarction of the non-fatal myocardium, but without reducing the number of coronary heart disease deaths or overall mortality [12]. In a secondary prevention study conducted by a group of Italian researchers, administration of $\alpha$-tocopherol at a dose of $300 \mathrm{mg}$ daily for 3.5 years did not reduce the risk of death or infarction Myocardium [13].

Another study was completed and showed that treatment with $\alpha$-tocopherol at a dose of $268 \mathrm{mg}$ per day for 4.5 years apparently had no effect on the cardiovascular future of high-risk patients [14]. Overall, the studies conducted so far do not provide any convincing evidence to recommend vitamin E supplementation as a public health measure. There are, however, many data concerning the beneficial effects of vitamin $\mathrm{E}$ on metabolic processes involved in various diseases. Boscoboinik and his team have shown that $\alpha$-tocopherol, at physiological concentrations, inhibits vascular smooth muscle proliferation, a well-known and important process in the formation of the so-called intermediate atherosclerotic lesion [15]. After supplementation at a dose of $800 \mathrm{mg} /$ day for 8 weeks in healthy subjects, another group observed decreased reactive oxygen release, lipid peroxidation, interleukin-1 $\beta$ secretion, and The adhesion of monocytes to endothelial cells [16].

In addition, inhibition of platelet aggregation after taking vitamin E was observed at doses of 268 to $804 \mathrm{mg}$ of $\alpha$-tocopherol/day [17]. These effects are not related to the antioxidant properties of vitamin E, as they do not occur with other liposoluble antioxidants. On the contrary, it appears that $\alpha$-tocopherol exerts direct effects on the expression of genes such as those of adhesive molecules [18] or on the activity of enzymes such as 5-lipoxygenase [19] or protein kinase C [17]. These results indicate that vitamin $\mathrm{E}$ may have beneficial effects on cardiovascular disease through a variety of mechanisms. However, as these studies have been conducted with vitamin E supplements at high doses, it remains to be seen whether these effects can be manifested with taking vitamin $\mathrm{E}$ at doses naturally present in foods such as olive oil. Although the intervention trials mentioned above have not shown convincing protective effects of vitamin E, even in the case of high-dose supplementation, this may be due in particular to the fact that atherogenesis is a process And that the oxidative modification of the lipoproteins is considered as one of the initial phenomena of the formation of atherosclerotic lesions.

The real value of vitamin $\mathrm{E}$ in feeding may therefore not be apparent until long-term primary prevention studies have been conducted [20]. This type of primary prevention studies has already been performed in animal models of atherosclerosis. Pratico and his team have thus been able to show that oxidative stress plays an important functional role in the development of atherosclerosis on an animal model and that the oral administration of vitamin $\mathrm{E}$ makes it possible to block this oxidative stress and the formation of atherosclerotic lesions of the aorta [21].

In addition, a study published by Terasawa Showed that an artificial vitamin E deficiency increases the severity of atherosclerosis in the same model in mice [22]. In addition to its expected beneficial effects in cardiovascular disease, vitamin $\mathrm{E}$ is an effective weapon against cancer. In many animal models, it has been shown that vitamin E protects against cancers of various locations [23]. In addition, human studies have shown that low serum or plasma levels of vitamin E are accompanied by an increased risk of lung, cervical and prostate cancer. Intervention trials in humans to date have also shown promising 
initial results. Heinonen and his team [24] found that long-term supplementation (5-8 years) with a-tocopherol at a dose of $50 \mathrm{mg}$ per day lowered the incidence of prostate cancer $(-32 \%)$ and mortality due to this cancer (-41\%). In a study of the effects of vitamin E on precancerous lesions of the upper aerodigestive tract, favorable clinical and histological responses were observed with high doses of $\alpha$-tocopherol (268 mg/day) [25].

In China, in rural Linxian, which is known for its high frequency of cancers, supplementation combining-tocopherol (30 mg/day), and selenium (50 $\mu \mathrm{g} /$ day) and-carotene $(15 \mathrm{mg} /$ Day) decreased mortality by $9 \%$. This decrease was mainly due to the low incidence of cancers, especially the stomach, and the risk reduction began to appear one to two years after the start of supplementation [26].

In conclusion, the many studies that have examined the health effects of vitamin $\mathrm{E}$ to date show that this micronutrient is likely to have beneficial effects. Some of these effects may only occur with high-dose supplementation. Nevertheless, vitamin E, in quantities where it is present in olive oil, is probably beneficial to health. Moreover, it is very likely that, due to synergistic effects, the combination of vitamin $\mathrm{E}$ and other minor components present in extra virgin olive oil has more beneficial effects than the sum of those of the individual components taken in isolation.

\section{Phenolic compounds}

It has often been shown that phenolic compounds are potent antioxidants. Owen and colleagues evaluated the antioxidant potential of different phenolic compounds of olive oil and observed that many of these compounds have antioxidant properties, such as hydroxytyrosol, tyrosol, Caffeic acid, vanillic acid, (+)-1-acetoxypinoresinol and oleuropein [27]. Interestingly, extracts of extra virgin olive oil (but no refined olive oil), containing a mixture of known and unknown phenolic compounds, were found to be effective at much lower concentrations than Various compounds studied one by one: this shows that there are synergistic effects between the various compounds which increase the antioxidant potential of the mixture.

In addition, extra virgin olive oil extracts had a major suppressive effect on xanthine oxidase activity. Xanthine oxidase is an enzyme involved in carcinogenesis and its inhibitors has been shown to have a chemo-preventive effect on cancer cells [27]. The sensibility of the LDL in the oxidation gave rise to similar observations. It was shown that the oleuropéine and the tyrosol inhibit in vitro the oxidation of the LDL, but a mixture of phenolic compounds of the extra virgin olive oil, in similar concentrations, allowed to obtain a much more marked result $[28,29]$.

Inaddition, protocatechuicacidand3,4-hydroxyphenylethanol (DHPE) have been shown to be very effective in protecting LDL from in vitro oxidation [30]. In these studies, LDLs were isolated and the phenolic compounds were added to the LDL preparations in vitro. However, Bonanome and his team administered meals rich in extra virgin olive oil to healthy volunteers and observed that, immediately after the meal, the phenolic compounds (in this case, the dosage was tyrosol and hydroxytyrosol ) were present in all classes of plasma lipoproteins except those of very low density (VLDL), which was accompanied by an increase in their ability to withstand oxidation [31]. DHPE has also been shown to be opposed to the cytotoxic effect of reactive oxygen metabolites on cells, thereby preventing cell damage [32].

Deiana and his team observed that hydroxytyrosol inhibits peroxynitrite-induced lesions in DNA [33]. In addition to these antioxidant effects, the phenolic compounds of extra virgin olive oil exert a clear anti-inflammatory action. Petroni and his team have shown that hydroxytyrosol inhibits, in a dose-dependent manner, the formation of a pro-inflammatory eicosanoid, leukotriene B4 [34]. Puerta found that hydroxytyrosol but also tyrosol, oleuropein and caffeic acid inhibit the formation of leukotriene B4 by reducing the activity of the enzyme that catalyses this formation, 5-lipoxygenase [35]. It has also been reported that this enzyme is inhibited by olive extract and that the substances responsible for this effect are DHPE, oleuropein and caffeic acid [36]. Another effect of olive oil phenols on health, interesting and perhaps beneficial, was reported by Petroni and his team. Perhaps also via 5-lipoxygenase inhibition, DHPE and to a lesser extent oleuropein, luteolin, apigenin and quercitine inhibit platelet aggregation and in vitro formation in vitro, Eicosaenoids by platelets [37].

\section{Aromatic compounds}

The leaf and fruit of the olive tree are known for their natural resistance to microbes and insects. Kubo and his team have discovered one of the reasons for this phenomenon, by observing the antimicrobial activity of molecules belonging to the large group of aromatic compounds [38]. Among these molecules were non-cyclic compounds such as hexanal, nonanal, 1-hexanol, 3-hexanal, 2-heptenal or 2-nonenal, as well as monoand sesquiterpene cyclic hydrocarbons such as 3-carene or $\beta$-farnesene. Most of these compounds had antimicrobial activity against a range of organisms, including Staphylococcus aureus, Streptococcus mutans, Escherichia coli, Candida utilis, and Aspergillus niger [38]. The implications of these results are not yet well known, but as some of these bacteria and fungi, or the toxins they produce, are dangerous to humans, this antimicrobial protection is an additional factor that can contribute to beneficial effects of olive oil on health.

\section{Impact of Minor Components on the Stability of Olive Oil}

The minor components of olive oil which have been mentioned above are not limited to having beneficial effects on health: they are also important for the shelf life and stability of the oil. Several teams have shown, independently of each other, that there is a strong correlation between the extra virgin olive oil 
content of phenolic compounds and its stability $[2,39,40]$. There is less agreement on whether tocopherol also contributes to stability. While Baldioli and his team did not find any correlation between the stability of the oil to oxidation and its $\alpha$-tocopherol content [39], others attributed a small role to $\alpha$-tocopherol [40] and a Spanish group even found a strong correlation between the stability of the oil to oxidation and its content of $\alpha$-tocopherol [2].

\section{Conclusion}

Olive oil, and especially extra virgin olive oil, contains a large number of structurally heterogeneous compounds, present at very low concentrations. Among these so-called minor components are vitamins such as tocopherols (vitamin E), phenols, hydrocarbons, sterols and aromatic compounds. These substances are responsible for the unique taste and fragrance of olive oil, increase stability and are beneficial to health by preventing deleterious processes such as oxidation of lipids by oxygen radicals. The presence of these compounds is in addition to the beneficial composition of the fatty acid oil so that olive oil can be recommended as one of the main sources of fat in our daily diet.

\section{References}

1. Kiritsakis A, Markakis P (1988) Olive oil: a review. Adv Food Res 31: 453-482.

2. Gutiérrez F, Jímenez B, Ruíz A, Albi MA (1999) Effect of olive ripeness on the oxidative stability of virgin olive oil extracted from the varieties Picual and Hojiblanca and on the different components involved. J Agric Food Chem 47(1): 121-127.

3. Psomiadou E, Tsimidou M, Boskou D (2000) $\alpha$-Tocopherol content of Greek virgin olive oils. J Agric Food Chem 48(5): 1770-1775.

4. Owen R, Mier W, Giacosa A, Hull WE, Spiegelhalder B, et al. (2000) Phenolic compounds and squalene in olive oils: the concentration and antioxidant potential of total phenols, simple phenols, secoiridoids, lignansand squalene. Food Chem Toxicol 38(8): 647-659.

5. Boskou D (2000) Olive oil, in Mediterranean diets. Karger Publishers, Basel, Switzerland p. 56-77.

6. Brenes M, García A, García P, Rios JJ, Garrido A (1999) Phenolic compounds in Spanish olive oils. Journal of Agricultural and Food Chemistry 47(9): 3535-3540.

7. Visioli F, Galli C, Bornet F, Mattei A, Patelli R (2000) Olive oil phenolics are dose-dependently absorbed in humans. FEBS letters 468(2-3): 159-160.

8. Stark AH, Madar PZ (2002) Olive oil as a functional food: epidemiology and nutritional approaches. Nutr Rev 60(6): 170-176.

9. Perez-Jimenez F, Alvarez de Cienfuegos G, Badimon L, Barja G, Battino $M(2005)$ International conference on the healthy effect of virgin olive oil. Eur J Clin Invest 35(7): 421-424.

10. Jha P, Flather M, Lonn E, Farkouh M, Yusuf S (1995) The antioxidant vitamins and cardiovascular disease: a critical review of epidemiologic and clinical trial data. Annals of Internal Medicine 123(11): 860-872.

11. Stampfer MJ, Rimm EB (1995) Epidemiologic evidence for vitamin E in prevention of cardiovascular disease. The American journal of clinical nutrition 62(6): 1365S-1369S.

12. Stephens NG, Parsons A, Schofield PM, Kelly F, Cheeseman K, et al.
(1996) Randomised controlled trial of vitamin E in patients with coronary disease: Cambridge Heart Antioxidant Study (CHAOS). Lancet 347(9004): 781-786.

13. Investigators GP (1999) Dietary supplementation with n-3 polyunsaturated fatty acids and vitamin $\mathrm{E}$ after myocardial infarction: results of the GISSI-Prevenzione trial. Gruppo Italiano per lo Studio della Sopravvivenza nell'Infarto miocardico. Lancet 354(9177): 447455.

14. Yusuf S, Dagenais G, Pogue J, Bosch J, Sleight P (2000) Vitamin E supplementation and cardiovascular events in high-risk patients. N Engl J Med 342(3): 154-160.

15. Boscoboinik D, Szewczyk A, Hensey C, Azzi A (1991) Inhibition of cell proliferation by alpha-tocopherol. Role of protein kinase C. J Biol Chem 266(10): 6188-6194.

16. Devaraj S, Li D, Jialal I (1996) The effects of alpha tocopherol supplementation on monocyte function. Decreased lipid oxidation, interleukin 1 beta secretion, and monocyte adhesion to endothelium. J Clin Invest 98(3): 756-763.

17. Freedman JE, Farhat JH, Loscalzo J, Keaney JF Jr (1996) $\alpha$-Tocopherol inhibits aggregation of human platelets by a protein kinase C-dependent mechanism. Circulation 94(10): 2434-2440.

18. Islam KN, Devaraj S, Jialal I (1998) $\alpha$-Tocopherol enrichment of monocytes decreases agonist-induced adhesion to human endothelial cells. Circulation 98(21): 2255-2261.

19. Devaraj S, Jialal I (1999) $\alpha$-Tocopherol decreases interleukin-1 $\beta$ release from activated human monocytes by inhibition of 5-lipoxygenase. Arterioscler Thromb Vasc Biol 19(4): 1125-1133.

20. Steinberg D (1995) Clinical trials of antioxidants in atherosclerosis: are we doing the right thing? Lancet 346(8966): 36-38.

21. Praticò D, Tangirala RK, Rader DJ, Rokach J, Fitz Gerald GA (1998) Vitamin E suppresses isoprostane generation in vivo and reduces atherosclerosis in ApoE-deficient mice. Nat med 4(10): 1189-1192.

22. Terasawa Y, Ladha Z, Leonard SW, Morrow JD, Newland D, et al. (2000) Increased atherosclerosis in hyperlipidemic mice deficient in $\alpha$-tocopherol transfer protein and vitamin E. Proc Natl Acad Sci U S A 97(25): 13830-13834.

23. Shklar G, Oh SK (2000) Experimental Basis for Cancer Preventation by Vitamin E. Cancer investigation 18(3): 214-222.

24. Heinonen OP, Albanes D, Virtamo J, Taylor PR, Huttunen JK, et al. (1998) Prostate cancer and supplementation with $\alpha$-tocopherol and $\beta$-carotene: incidence and mortality in a controlled trial. J Natl Cancer Inst 90(6): 440-446.

25. Benner SE, Winn RJ, Lippman SM, Poland J, Hansen KS, et al. (1993) Regression of oral leukoplakia with $\alpha$-tocopherol: a community clinical oncology program chemoprevention study. J Natl Cancer Inst 85(1): 44-47.

26. Blot WJ, Li JY, Taylor PR, Guo W, Dawsey S (1993) Nutrition intervention trials in Linxian, China: supplementation with specific vitamin/mineral combinations, cancer incidence, and disease-specific mortality in the general population. J Natl Cancer Inst 85(18): 1483-1491.

27. Owen R, Giacosa A, Hull WE, Haubner R, Spiegelhalder B (2000) The antioxidant/anticancer potential of phenolic compounds isolated from olive oil. Eur J Cancer 36(10): 1235-1247.

28. Visioli F, Galli C (1994) Oleuropein protects low density lipoprotein from oxidation. Life Sci 55(24): 1965-1971.

29. Caruso D, Giavarini F , Cortesi N , Fedeli E, Galli G, et al. (1999) Effect of virgin olive oil phenolic compounds on in vitro oxidation of human low density lipoproteins. Nutrition, metabolism, and cardiovascular diseases: NMCD 9(3): 102-107. 
30. Masella R, Cantafora A, Modesti D, Cardilli A, Gennaro L, et al. (1999) Antioxidant activity of 3, 4-DHPEA-EA and protocatecuic acid: a comparative assessment with other olive oil biophenols. Redox Rep 4(3): 113-121.

31. Bonanome A, Pagnan A, Caruso D, Toia A, Xamin A, et al. (2000) Evidence of postprandial absorption of olive oil phenols in humans. Nutrition, metabolism, and cardiovascular diseases: NMCD 10(3): 111120

32. Manna C, Galletti P, Cucciolla V, Moltedo O, Leone A, et al. (1997) The protective effect of the olive oil polyphenol (3, 4-dihydroxyphenyl)ethanol counteracts reactive oxygen metabolite-induced cytotoxicity in Caco-2 cells. J Nutr 127(2): 286-292.

33. Deiana M, Aruoma OI, Bianchi ML, Spencer JP, Kaur H, et al. (1999) Inhibition of peroxynitrite dependent DNA base modification and tyrosine nitration by the extra virgin olive oil-derived antioxidant hydroxytyrosol. Free Radic Biol Med 26(5-6): 762-769.

34. Petroni A, Blasevich M, Papini N, Salami M, Sala A, et al. (1997) Inhibition of leukocyte leukotriene B 4 production by an olive oil-derived phenol identified by mass-spectrometry. Thromb Res 87(3): 315-322.
35. de la Puerta R, Gutierrez VR, Hoult JRS (1999) Inhibition of leukocyte 5 -lipoxygenase by phenolics from virgin olive oil. Biochem Pharmacol 57(4): 445-449.

36. Kohyama N, Nagata T, Fujimoto S, Sekiya K (1997) Inhibition of arachidonate lipoxygenase activities by 2-(3, 4-dihydroxyphenyl) ethanol, a phenolic compound from olives. Biosci Biotechnol Biochem 61(2): 347-350.

37. Petroni A, Blasevich M, Salami M, Papini N, Montedoro GF, et al. (1995) Inhibition of platelet aggregation and eicosanoid production by phenolic components of olive oil. Thrombosis research 78(2): 151-160.

38. Kubo A, Lunde CS, Kubo I (1995) Antimicrobial activity of the olive oil flavor compounds. Journal of Agricultural and Food Chemistry 43(6): 1629-1633.

39. Baldioli M, Servili M, Perretti G, Montedoro GF (1996) Antioxidant activity of tocopherols and phenolic compounds of virgin olive oil. Journal of the American Oil Chemists' Society 73(11): 1589-1593.

40. Aparicio R, Roda L, Albi MA, Gutiérrez F (1999) Effect of various compounds on virgin olive oil stability measured by Rancimat. J Agric Food Chem 47(10): 4150-4155.

\section{Your next submission with Juniper Publishers will reach you the below assets}

- Quality Editorial service

- Swift Peer Review

- Reprints availability

- E-prints Service

- Manuscript Podcast for convenient understanding

- Global attainment for your research

- Manuscript accessibility in different formats ( Pdf, E-pub, Full Text, Audio)

- Unceasing customer service

Track the below URL for one-step submission https://juniperpublishers.com/online-submission.php 